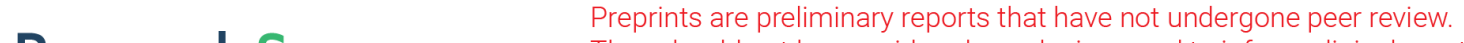 They should not be considered conclusive, used to inform clinical practice, or referenced by the media as validated information. \\ Definition and Quantified Research of Track Structural Damage Index of High-speed Railway Girder Bridge
}

\section{Zhangliang Hu}

Central South University School of Civil Engineering

Biao Wei ( $\nabla$ weibiao@csu.edu.cn )

Central South University School of Civil Engineering

\section{Lizhong Jiang}

Central South University School of Civil Engineering

Shanshan Li

Central South University School of Civil Engineering

Haozheng Min

Central South University School of Civil Engineering

\section{Research Article}

Keywords: high-speed railway girder bridges (HRGBs), train safety, train stability, track damage grade, train-track-bridge system (TTBS), lateral displacement of rail

Posted Date: March 7th, 2022

DOI: https://doi.org/10.21203/rs.3.rs-1391240/v1

License: (c) (1) This work is licensed under a Creative Commons Attribution 4.0 International License. Read Full License 


\title{
Definition and Quantified Research of Track Structural Damage Index of High-speed Railway Girder Bridge
}

\author{
Zhangliang $\mathrm{Hu}^{1,2}$, Biao Wei ${ }^{1,2, *}$, Lizhong Jiang ${ }^{1,2}$, Shanshan $\mathrm{Li}^{1,2}$, Haozheng Min ${ }^{1,2}$ \\ ${ }^{a}$ School of Civil Engineering, Central South University, Changsha 410075, China \\ ${ }^{b}$ National Engineering Research Center of High-speed Railway Construction Technology, Changsha 410075, China \\ ${ }^{*}$ Corresponding author. Tel.:+86 14789706432; Fax: +86 73182656611 \\ E-mail addresses: huzhangliang@csu.edu.cn (ZL Hu),weibiao@csu.edu.cn (B Wei), lzhjiang@csu.edu.cn (LZ Jiang), \\ shanshanli@csu.edu.cn (SS Li), 204811054@csu.edu.cn (HZ Min)
}

\begin{abstract}
The classification and quantitative description of damage of track structure for high-speed railway girder bridges (HRGBs) are still in the exploratory stage, which seriously interferes with the performance-based seismic damage assessment of HRGBs. In view of this, firstly, from the safety and stability of train operation, this paper defines the damage grade of track structure (intact, slight, moderate, severe and complete damage state) by refining the train operation index value. Secondly, based on the simple supported and continuous girder bridge structures of high-speed railway, the train-track-bridge system (TTBS) model is established, and the additional lateral irregularities of the rail caused by the lateral deform of the girder after the earthquake are induced. Finally, the influence of the lateral displacement amplitude of the rail and the train velocity on the train safety and stability is discussed. The results indicate that the rail lateral displacement by the reverse translation of the adjacent simply supported spans and the reverse rotation of the adjacent simply supported spans have the greatest impact on the train safety and stability, respectively. The lateral displacement of rail is proposed as an index to measure the damage of the track structure, and its critical value corresponding to each damage grade in the range of train velocity from $200 \mathrm{~km} / \mathrm{h}$ to $400 \mathrm{~km} / \mathrm{h}$ is determined, which can be used for the seismic vulnerability analysis of track structures for HRGBs.
\end{abstract}

Key words: high-speed railway girder bridges (HRGBs); train safety; train stability; track damage grade; train-track-bridge system (TTBS); lateral displacement of rail

\section{Introduction}

The rapid development of railway transportation has forced high-speed railway lines to inevitably cross near faults and high-intensity seismic zones, and even be arranged across faults, which puts forward higher requirements for the bridge structure in the line. Accordingly, the accurate assessment of the damage of high-speed railway bridges (HRBs) under the action of earthquakes is very significant for the structural mechanics of the bridge itself and the safety of trains on the bridge. Currently, the probability-based seismic vulnerability analysis method is still a key medium for accessing the overall seismic performance of HRBs. Among them, the classification of damage grades of components and the quantification of damage indicators directly affect the damage probability, which in turn affects the damage evaluation of the whole bridge system.

In practical terms, a large number of damage assessments are currently carried out only for bridge structures in HRBs. Jiang et al. (2017) calculated the damage exceedance probability of the piers and bearings of a HRB arranged as the continuous beam bridge in terms of the incremental dynamic analysis method. Park and Towashiraporn (2014) established a response surface model for seismic damage assessment of HRBs, but the assessment objects are also limited to piers and bearings. In recent years, track-bridge integral models composed of ballastless track slabs and continuous 
girder bridges for high-speed railways was established, the optimal ground motion intensity measure was compared, the seismic performance of the bridge and track as a whole was evaluated from the perspective of component and system damage probability, and sensitivity analysis of component damage probability on ground motion characteristic period, vertical component of seismic waves and ground motion induced angles were carried out (Hu et al. 2022; Wei et al. 2018a, b, 2021). In the existing investigation on seismic vulnerability analysis of HRB, the component damage indicators of bridge structures such as piers and bearings can follow the definition of that in highway bridges. For example, material strain, section curvature, displacement ductility, and Park-Ang damage indicators can be used as damage indicators of high-speed railway piers (Kowalsky 2000; Pan et al. 2007; Nielson and DesRoches 2007; Cao et al. 2019). The deformation of the bearing itself or the relative position of the girder end can be used to determine the bearings of HRBs (Hu et al. 2022). The track is an interlayer structure composed of base plate, track slab and rail and connecting by CA mortar layer and fasteners. The interlayer connecting components are prone to accumulative damage under an earthquake action (Kang et al. 2017). However, it is difficult to define the damage of connecting members between track layers through investigation and statistics due to the lack of actual seismic damage data for HRBs. Therefore, the damage index of track interlayer connecting components is often defined empirically according to the test data, such as yield stress and elastic-plastic critical point displacement of CA mortar layer and fasteners (Dai and Liu 2013). For example, the deformation of fasteners up to $2 \mathrm{~mm}, 3 \mathrm{~mm}, 4 \mathrm{~mm}$ and $5 \mathrm{~mm}$ were defined as the threshold values for the intact, mild, moderate, severe and complete damage states of the fasteners. Such defined damage index only from the perspective of deformation of the component itself, but fails to consider the impact of its own deformation on the train on the rail, so the damage critical value of the track structure connector defined by this method is worth further discussion.

Derailment coefficient and wheel load reduction rate are usually used to judge train safety, and train operation stability is often reflected by car body acceleration and Sperling index (Luo 2005). The premise of directly selecting train operation index as the damage index of HRB is to establish the large-scale system model of TTBS and complex wheel-rail contact relationship. The precise TTBS integrated finite element model usually relies on solid finite element software (Yu et al. 2021), which involves massive element meshing and various nonlinear materials and contact properties, especially wheel-rail contact. It is not only time-consuming but also consumes a lot of resources when conducting a large number of nonlinear time history calculations. Whereas, the simplified TTBS integrated finite element model fails to reflect the nonlinearity between the piers, foundations and connecting components, resulting in distortion of the calculation results (Liu et al. 2020). Consequently, the seismic vulnerability analysis of HRBs based on train operation index is still difficult to carry out. Jin et al. $(2016,2020)$ applied the concept of seismic vulnerability to the evaluation of derailment for the first time, and proposed to take the relative displacement of train wheels and rails as the damage index of train derailment, that is, the displacement corresponding to the loss of wheel-rail contact, the lowest point of wheel higher than the highest point of track and the complete departure of wheel from track, so as to obtain the failure probability of train derailment at different train speeds, but it does not consider the additional irregularity effect of the track. Differential foundation settlement and creep effect of concrete deck will bring additional irregularity to the track. Therefore, focusing on the vertical additional irregularity of track, many scholars have obtained the safe values of pier settlement displacement and bridge vertical deformation for controlling the train safety and stability (Zhang et al. 2017; Gou et al. 2019; Zheng et al. 2020; Chen and Zhai 2020). In addition, the track is laterally deformed by the horizontal component of the seismic waves. As a result, the influence of the lateral irregularity on the train operation has attracted attention. Gou et al. (2018) deduced the correlation between rail and bridge deformation, and analyzed the sensitivity of mechanical parameters of track connectors to rail deformation. Lai et al. (2021) obtained the additional track irregularities caused by the lateral deformation of the girder after the earthquake and initial track irregularities, and input them into the TTBS model. Then, the threshold value of girder lateral displacement amplitude to ensure train safety 
and passenger comfort was obtained. This means that external excitations such as earthquakes cause the track to deform, causing additional irregularities to the track, which seriously interfere with the train safety and stability. However, the influence of the above-mentioned lateral additional irregularities on the train operation is only concentrated on the small-span simply supported girder bridge, and only one safety limit of deformation is obtained. The critical index values corresponding to the various seismic performance grades are not given according to the idea of multi-level fortification level, so they cannot be directly used for the performance-based seismic vulnerability assessment of track structure for HRBs.

When the train is running at high speed, the irregularity of the track excites the train wheelset, and the wheelset collides with the rail, thus realizing the train-bridge coupling effect. The initial track irregularity directly causes the interaction between the wheel and the rail, and then affects the train safety and comfort. The influence of the initial irregularity superimposed on the lateral additional irregularity after the earthquake on the train operation cannot be ignored. Accordingly, establishing the corresponding relationship between rail lateral deformation and train safety and stability, characterizing the running characteristics of trains with rail deformation, and determining rail deformation as the index of track damage is worthy of in-depth investigate. And it is also reasonable to judge the track damage from the perspective of comprehensively considering the rail displacement itself and the control of the rail displacement on the train safety and stability. Besides, the seismic vulnerability analysis of HRBs is mostly based on the track-bridge model (Yu et al. 2017; Wei et al. 2019, 2020), so the proposed rail deformation as the index of track damage can provide a basis for the determination of track damage under earthquake, and it has wide applicability.

In light of this, in this paper, the lateral displacement of rail is proposed as the damage index of track structure, and its quantification is studied. First, based on the idea of performance-based seismic design, the hierarchical seismic performance level of track structure, i.e. damage level, is defined. Next, by establishing the TTBS model of a HRGB, the effects of track lateral deformation amplitude and train velocity on train safety and stability are analyzed. Finally, the lateral deformation of rail is determined according to the threshold of running index corresponding to each damage level, so as to quantify the damage of track structure of HRGBs.

\section{Determination of damage grade of track structure}

The damage grade of track structure in this paper is defined by refining the train safety and stability indexes in the current code. Therefore, the train safety index and the stability index are briefly introduced first.

\subsection{Train safety index}

Train derailment is generally applied to measure the running safety of high-speed railway trains. At present, the most widely used indicators to judge train derailment are derailment coefficient, wheel load reduction rate and wheel axle lateral force.

(1) Derailment coefficient

The derailment coefficient is calculated according to the ratio of the lateral force $(Q)$ to the vertical force $(P)$ between the wheel and rail, which can be derived from the equilibrium equations between the normal and tangential forces of the train, that is:

$$
\frac{Q}{P}=\frac{\tan \alpha-\mu}{1+\mu \tan \alpha}
$$

Where $\alpha$ is the flange angle, $\mu$ represents the friction coefficient between wheel and rail.

(2) Wheel load reduction rate

The wheel weight is always fluctuating during the train running, and the sharp reduction of wheel weight is easy to cause the train derailment. Therefore, the ratio of the wheel weight reduction value of one side to the average wheel weight is defined as the wheel load reduction rate, as follows: 


$$
\left\{\begin{array}{l}
\Delta P=\left(\left|P_{2}-P_{1}\right|\right) / 2 \\
\bar{P}=\left(P_{2}+P_{1}\right) / 2
\end{array}\right.
$$

Where $\Delta P$ is the load shedding value for wheel weight, $P_{1}$ and $P_{2}$ are the wheel weights on both sides, $\bar{P}$ is the average wheel weight on both sides.

(3) Wheel axle lateral force

Excessive wheel axle lateral force will aggravate the irregularity of the gauge and aggravate the derailment of the train. Therefore, the magnitude of wheel axle lateral force must be controlled. According to the code, i.e. "Testing of High-speed Electic Multiple Unit on Completion of Construction” (MR-PRC 2008), the safety limits of axle lateral force are as follows:

$$
H \leq 10+P_{0} / 3
$$

In which, $H$ represents the wheel axle lateral force, $P_{0}$ is the static axle weight of wheels.

\subsection{Train stability index}

(1) Acceleration of car body

The acceleration of car body caused by vibration during train operation seriously affects the stability of train, which in turn brings discomfort to the passengers. By reference to China's specification "Code for Design of High Speed Railway (2014)", the threshold values of vertical and lateral acceleration of car body during running on the rail are stipulated as follows:

$$
\begin{cases}a \leq 0.13 g & \text { (in vertical direction) } \\ a \leq 0.10 g & \text { (in lateral direction) }\end{cases}
$$

(2) Sperling index

The stability of the train operation can be specifically reflected in the riding comfort of passengers on the train, which can be quantified by Sperling index value and calculated according to formula (5):

$$
W_{z}=0.89610 \sqrt{\frac{a^{3}}{f} F(f)}
$$

Where $a$ is the car body vibration acceleration, $f$ is the vibration frequency, $F(f)$ represents the modifying coefficient of frequency.

The corresponding relationship between passenger comfort and Sperling index is shown in Table 1.

Table1. Correspondence between comfort and Sperling index.

\begin{tabular}{cc}
\hline Comfort level & Sperling index \\
\hline Visibly unwell & 2.0 \\
More obvious discomfort & 2.5 \\
Intense discomfort & 2.75 \\
Intense discomfort, but still tolerable & 3.0 \\
Extremely abnormal and troubled & 3.5 \\
Extremely disgusting & 4.0 \\
\hline
\end{tabular}

\subsection{Classification of track damage level}

Generally, the seismic performance or damage of the bridge or its components is divided into several grades based on the structural safety and service function. According to the traffic capacity, the ATC-32 specification divides the seismic performance levels of reinforced concrete bridges into four levels, that is, normal traffic, immediate traffic, life safety, and collapse prevention (Council 1996). In HAZUS, pier damage is defined as five grades, which are completely 
undamaged, mildly damaged, moderately damaged, severely damaged, and completely collapsed (Fema 1999). Drawing on this idea, the safety and stability indicators of the train are also divided into five grades, i.e. intact, slight, moderate, severe and complete damage, so as to define the damage grade of the track structure.

Currently, the operation velocity of high-speed railway is relatively high. For the train with design speed between $250 \mathrm{~km} / \mathrm{s}$ and $350 \mathrm{~km} / \mathrm{s}$, the limit value of derailment coefficient is 0.80 (Code for Design of High Speed Railway, 2014), which belongs to the dangerous limit, that is, when the derailment coefficient exceeds 0.80 , the train may derail, so this state can be regarded as a complete damage state. According to the code of China "Specification for dynamic performance testing verification method and assessment of railway locomotive" (MR-PRC 1993), the derailment coefficients of low-speed trains into dangerous, qualified, good and excellent grades, and the corresponding derailment coefficients are 1.20, 1.0, 0.8 and 0.6, respectively. Similarly, for high-speed train, the derailment coefficient can also be subdivided into the above four grades. The derailment coefficient of the corresponding grades is $0.80,0.67,0.53$ and 0.40 by scaling, which are defined as complete, severe, moderate and mild damage grades respectively. Wheel load reduction rate is also an important indicator to measure train derailment, and its limit value is 0.60 (MR-PRC 2008). This implies that when the wheel load reduction ratio exceeds 0.60 , the train is in all likelihood to derail, which can be considered as a complete damage state. Similar to the derailment coefficient, the wheel load reduction rate is also divided into four grades, and the scaled load reduction rates are $0.60,0.50,0.40$ and 0.30 , corresponding to the grades of complete, severe, moderate and slight damage state. Calculate the derailment coefficient and wheel load reduction rate respectively, and take the larger value to judge the train safety.

For the acceleration of the car body, the specification only gives the stability limit value. For example, the car body lateral acceleration is restricted to $1.0 \mathrm{~m} / \mathrm{s}^{-2}$. Therefore, it is also defined as four grades in proportion according to the driving safety classification method, with the values of $1.0 \mathrm{~m} / \mathrm{s}^{-2}, 0.83 \mathrm{~m} / \mathrm{s}^{-2}, 0.67 \mathrm{~m} / \mathrm{s}^{-2}$ and $0.5 \mathrm{~m} / \mathrm{s}^{-2}$ respectively, corresponding to the grades of complete, serious, medium and slight damage state. In addition, the stability level is defined according to passenger riding comfort, summarized in the Table 1. When Sperling index exceeds 2.0, passengers can feel uncomfortable, so this state is defined as slight damage state; when Sperling index exceeds 3.0, it is considered that the passengers feel strongly unwell, and this state is defined as complete damage state. The Sperling index values of 2.50 and 2.75 represent the moderate and severe damage state. Calculate the lateral acceleration value and Sperling index of the car body respectively, and take the larger value to judge the stability of the train.

Taking into account the train safety and stability, the damage grade of track structure is defined as shown in Table 2, in which, DS1 to DS4 represent the grade of slight, moderate, severe and complete damage state. The definition principle of track damage grade is: if the damage grade corresponding to train safety and stability index is consistent, then the damage grade corresponding to any index shall be taken; if the damage grade corresponding to train safety and stability index is inconsistent, then the higher damage grade shall be taken.

Table 2. Definition of damage grade of track structure.

\begin{tabular}{ccccc}
\hline Train stability: & \multicolumn{4}{c}{ Train safety: Derailment coefficient / Wheel load reduction ratio } \\
Sperling index / a & $0.40 / 0.30$ & $0.53 / 0.40$ & $0.67 / 0.50$ & $0.80 / 0.60$ \\
\hline $2.0 / 0.5 \mathrm{~m} / \mathrm{s}^{-2}$ & DS1 & DS2 & DS3 & DS4 \\
$2.5 / 0.67 \mathrm{~m} / \mathrm{s}^{-2}$ & DS2 & DS2 & DS3 & DS4 \\
$2.75 / 0.83 \mathrm{~m} / \mathrm{s}^{-2}$ & DS3 & DS3 & DS3 & DS4 \\
$3.0 / 1.0 \mathrm{~m} / \mathrm{s}^{-2}$ & DS4 & DS4 & DS4 & DS4 \\
\hline
\end{tabular}




\section{Train-track-bridge system model}

\subsection{Train model}

Trains operated by high-speed railway are generally equipped with several motor and trailer cars. A motor or trailer car consists of one car body, 2 front and rear bogies, and 4 wheel sets. The connection between wheel sets and bogies and between bogie and car body is called primary and secondary suspension system, exhibited in Fig. 1.

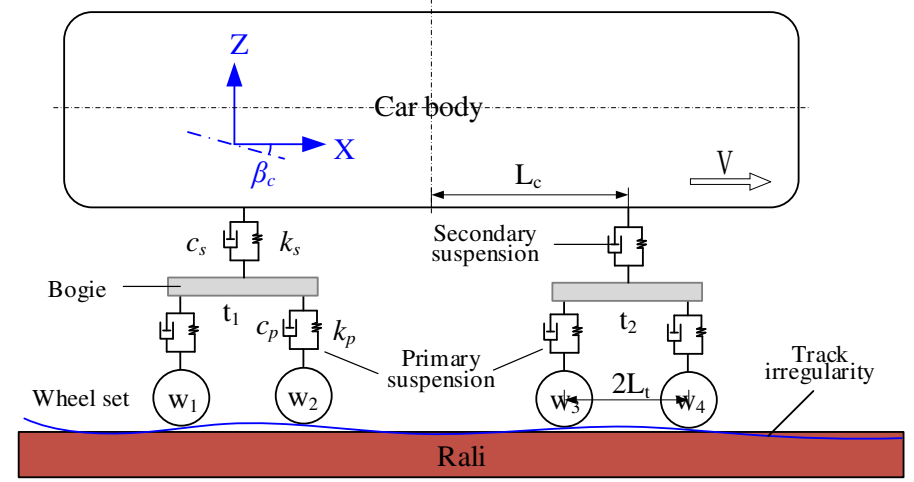

(a)

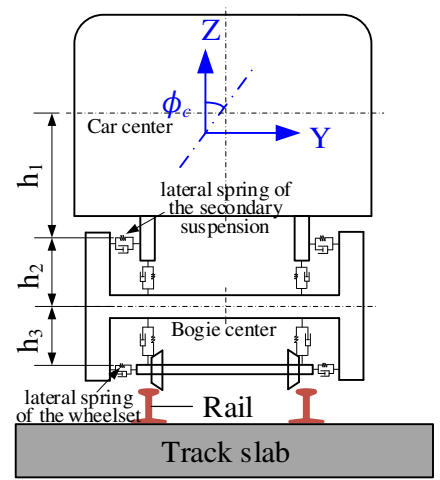

(b)

Fig.1. Schematic diagram of train model: (a) Front view; (b) Side view.

Due to the extremely complex geometric structure of the train, and the mechanical parameters change with the train type, it is extremely difficult to accurately simulate each part of the train. At present, the train model usually ignores its elastic deformation and regards the car body, bogie and wheel set as a multi-rigid body system. Therefore, rigid bodies are used to simplify the simulation of the above train components in this paper. The four-axle $\mathrm{CRH} 2$ train that is currently widely operated is used to establish the simplified train model in this paper. The geometric and mechanical parameters of each component of the train are shown in Table 3. According to the vibration behavior of the train, the car body and the bogie generally have 6 degrees of freedom (DOF), and the wheelset has 5 DOF. This paper does not consider the longitudinal vibration of the vehicle system, so the DOF of the car body and the bogie are defined as lateral movement, heave, roll, nod and shake head respectively, and the DOF of the wheel set are lateral movement, heave, roll and shake head, with a total of 31 DOF. In addition, the primary and secondary suspension systems are simplified with springs and damping, and both are assumed to be linear. According to the constant principle of the total potential energy of the train system, the vibration equation of the vehicle system can be derived by performing first-order variational processing:

$$
\mathbf{M}_{t} \mathbf{C}_{t} \mathbf{X}_{t}+\mathbf{K}_{t} \mathbf{X}_{t}=\mathbf{F}_{t}
$$

Where $\mathbf{M}_{t}, \mathbf{C}_{t}$ and $\mathbf{K}_{t}$ are mass, damping and stiffness matrices of train system; are the acceleration, and $\mathbf{X}_{t}$ are the acceleration, velocity and displacement matrices of each degree of freedom of the train; $\mathbf{F}_{t}$ represents the external force matrix in each degree of freedom direction of train components.

Table 3. Mechanical and geometric parameters of CRH2 trains.

\begin{tabular}{ccccc}
\hline Parameters & Abbreviation & Units & Motor & Trailer \\
\hline \multirow{2}{*}{ Mass } & car body $\left(\mathrm{m}_{\mathrm{c}}\right)$ & $\mathrm{kg}$ & 28880 & 44000 \\
& bogie $\left(\mathrm{m}_{\mathrm{t}}\right)$ & $\mathrm{kg}$ & 2600 & 2400 \\
& wheelset $\left(\mathrm{m}_{\mathrm{w}}\right)$ & $\mathrm{kg}$ & 1970 & 2400 \\
\hline \multirow{2}{*}{ Moment of inertia of car body } & around X-axis $\left(\mathrm{I}_{\mathrm{cx}}\right)$ & $\mathrm{kg} \cdot \mathrm{m}^{2}$ & 93312 & 100000 \\
& around $\mathrm{Y}$-axis $\left(\mathrm{I}_{\mathrm{cy}}\right)$ & $\mathrm{kg} \cdot \mathrm{m}^{2}$ & 1411200 & 2700000 \\
\hline
\end{tabular}




\begin{tabular}{|c|c|c|c|c|}
\hline & around $\mathrm{Z}$-axis $\left(\mathrm{I}_{\mathrm{cz}}\right)$ & $\mathrm{kg} \cdot \mathrm{m}^{2}$ & 1331712 & 2700000 \\
\hline \multirow{3}{*}{ Moment of inertia of bogie } & around $\mathrm{X}$-axis $\left(\mathrm{I}_{\mathrm{tx}}\right)$ & $\mathrm{kg} \cdot \mathrm{m}^{2}$ & 2106 & 2400 \\
\hline & around $\mathrm{Y}$-axis $\left(\mathrm{I}_{\mathrm{ty}}\right)$ & $\mathrm{kg} \cdot \mathrm{m}^{2}$ & 1424 & 5400 \\
\hline & around $\mathrm{Z}$-axis $\left(\mathrm{I}_{\mathrm{tz}}\right)$ & $\mathrm{kg} \cdot \mathrm{m}^{2}$ & 2600 & 5100 \\
\hline \multirow{2}{*}{ Moment of inertia of wheelset } & around $\mathrm{X}$-axis $\left(\mathrm{I}_{\mathrm{wx}}\right)$ & $\mathrm{kg} \cdot \mathrm{m}^{2}$ & 623 & 1200 \\
\hline & around $\mathrm{Z}$-axis $\left(\mathrm{I}_{\mathrm{wz}}\right)$ & $\mathrm{kg} \cdot \mathrm{m}^{2}$ & 623 & 1200 \\
\hline \multirow{3}{*}{ Stiffness of primary suspension } & $\mathrm{X}$-axis $\left(\mathrm{k}_{\mathrm{px}}\right)$ & $\mathrm{N} / \mathrm{m}$ & 980000 & 15000000 \\
\hline & $\mathrm{Y}$-axis $\left(\mathrm{k}_{\mathrm{py}}\right)$ & $\mathrm{N} / \mathrm{m}$ & 980000 & 5000000 \\
\hline & $\mathrm{Z}$-axis $\left(\mathrm{k}_{\mathrm{pz}}\right)$ & $\mathrm{N} / \mathrm{m}$ & 1176000 & 7000000 \\
\hline \multirow{3}{*}{ Damping of primary suspension } & $\mathrm{X}$-axis $\left(\mathrm{c}_{\mathrm{px}}\right)$ & $\mathrm{N} / \mathrm{m} \cdot \mathrm{s}$ & 0 & 0 \\
\hline & Y-axis $\left(c_{p y}\right)$ & $\mathrm{N} / \mathrm{m} \cdot \mathrm{s}$ & 0 & 0 \\
\hline & Z-axis $\left(c_{\mathrm{pz}}\right)$ & $\mathrm{N} / \mathrm{m} \cdot \mathrm{s}$ & 19600 & 50000 \\
\hline \multirow{3}{*}{ Stiffness of secondary suspension } & $\mathrm{X}$-axis $\left(\mathrm{k}_{\mathrm{sx}}\right)$ & $\mathrm{N} / \mathrm{m}$ & 166600 & 280000 \\
\hline & $\mathrm{Y}$-axis $\left(\mathrm{k}_{\mathrm{sy}}\right)$ & $\mathrm{N} / \mathrm{m}$ & 166600 & 560000 \\
\hline & $\mathrm{Z}$-axis $\left(\mathrm{k}_{\mathrm{sz}}\right)$ & $\mathrm{N} / \mathrm{m}$ & 176400 & 300000 \\
\hline \multirow{3}{*}{ Damping of secondary suspension } & $\mathrm{X}$-axis $\left(\mathrm{c}_{\mathrm{sx}}\right)$ & $\mathrm{N} / \mathrm{m} \cdot \mathrm{s}$ & 0 & 120000 \\
\hline & Y-axis ( $\left.\mathrm{c}_{\mathrm{sy}}\right)$ & $\mathrm{N} / \mathrm{m} \cdot \mathrm{s}$ & 58800 & 25000 \\
\hline & $\mathrm{Z}$-axis $\left(\mathrm{c}_{\mathrm{sz}}\right)$ & $\mathrm{N} / \mathrm{m} \cdot \mathrm{s}$ & 9800 & 60000 \\
\hline Half of fixed distance of car body & $\left(\mathrm{L}_{\mathrm{c}}\right)$ & $\mathrm{m}$ & 8.75 & 9.0 \\
\hline Half of wheelset wheelbase & $\left(\mathrm{L}_{\mathrm{t}}\right)$ & $\mathrm{m}$ & 1.23 & 1.25 \\
\hline- & $\left(\mathrm{h}_{1}\right)$ & $\mathrm{m}$ & 0.569 & 0.83 \\
\hline- & $\left(\mathrm{h}_{2}\right)$ & $\mathrm{m}$ & 0.39 & 0.15 \\
\hline- & $\left(\mathrm{h}_{3}\right)$ & $\mathrm{m}$ & 0.185 & 0.34 \\
\hline Radius of wheelset & $\left(\mathrm{r}_{0}\right)$ & $\mathrm{m}$ & 0.46 & 0.46 \\
\hline
\end{tabular}

\subsection{Track structure model}

Ballastless type II track slab (CRTS II) is widely applied in high-speed railway passenger dedicated line because of its excellent stability (Yan et al. 2017). CRTS II ballastless track consists of steel rail, fastener, track plate, CA mortar layer, base plate and sliding layer connecting the base plate and bridge deck. The rail, track slab and base plate are modeled by beam element, and the unit length is taken as the fastener spacing, i.e. $0.65 \mathrm{~m}$. Fasteners, CA mortar layer and sliding layer are connected by springs and give stiffness in the direction of longitudinal, transverse and vertical. The components contributing to the elastic potential energy are collected to form the total elastic potential energy of CRTSII ballastless track. Then, performing first-order variational processing, the element mass, stiffness matrix and nodal load array can be obtained. Next, the total mass, stiffness and node load matrix of track structure are assembled according to the degrees of freedom of track structure, and the damping matrix is obtained by the mass and stiffness matrix multiplying the corresponding coefficients. Finally, the vibration equation of track structure is obtained as follows:

$$
\mathbf{M}_{C R T S}+\mathbf{C}_{C R T S} \mathbf{X}_{C R T S}+\mathbf{K}_{C R T S} \mathbf{X}_{C R T S}=\mathbf{F}_{C R T S}
$$

Where $\mathbf{M}_{C R T S}, \mathbf{C}_{C R T S}$ and $\mathbf{K}_{C R T S}$ are mass, damping and stiffness matrices of ballastless track structure; $\mathbf{X}_{C R T S}^{\&}$ and $\mathbf{X}_{C R T S}$ are acceleration, velocity and displacement matrices in each degree of freedom direction of ballastless track structure; $\mathbf{F}_{C R T S}$ represents the node load matrix.

\subsection{Bridge model}

At present, high-speed railway simply supported and continuous girder bridges account for a large proportion of HRGBs. Therefore, simply supported $(3 \times 32 m)+$ continuous $(48 m+80 m+48 m)+$ simply supported $(3 \times 32 m)$ with a total 
of 9 spans are selected as the bridge structure supporting the ballastless track. The girder and pier are built by beam elements, the length of the girder element is the same as the fastener spacing, and the length of the pier element is $1 \mathrm{~m}$. The bearings and foundations are modeled with spring elements, imparting stiffness and damping. Adopting the finite element theory, the mass and stiffness matrix of the bridge structure can be determined, and the overall damping matrix can be derived by the proportional combination of the two. Therefore, the spatial vibration equation of the bridge structure is:

$$
\mathbf{M}_{b}+\mathbf{C}_{b} \mathbf{X}_{b}+\mathbf{K}_{b} \mathbf{X}_{b}=\mathbf{F}_{b}
$$

Where $\mathbf{M}_{b}, \mathbf{C}_{b}$ and $\mathbf{K}_{b}$ are the mass, damping and stiffness matrices of the bridge structure; $\mathbf{X}_{b}$ and $\mathbf{X}_{b}$ are the acceleration, velocity and displacement matrices of each degree of freedom of the bridge structure; $\mathbf{F}_{b}$ represents the load matrix of the bridge structure nodes.

\subsection{Wheel-rail contact}

The coupling between the train and the bridge is realized by the wheel-rail contact. It is difficult to accurately simulate the wheel-rail contact relationship, because the wheel rail contact changes with time and space, so the wheel-rail contact is often simplified. The contact between the train wheel and the rail will generate normal force and tangential creep force. The wheel-rail contact normal force is calculated using the Herz contact theory, and the creep force is generally computed in terms of the Shen-Hedrick-Elkins method. The detailed calculation theory and process have been described in many literatures (Shen et al. 2007; Zhai et al. 2013), which will not be repeated here.

The TTBS model is compiled by Matlab program, and the finally established TTBS model is presented in Fig. 2. Besides, a subgrade section with a length of $400 \mathrm{~m}$ is manually added to the model for eliminating the boundary effect of the rails in the subgrade section. The accuracy of this TTBS model was verified by comparing the field measured data with the model calculation results (Xiang et al. 2021).

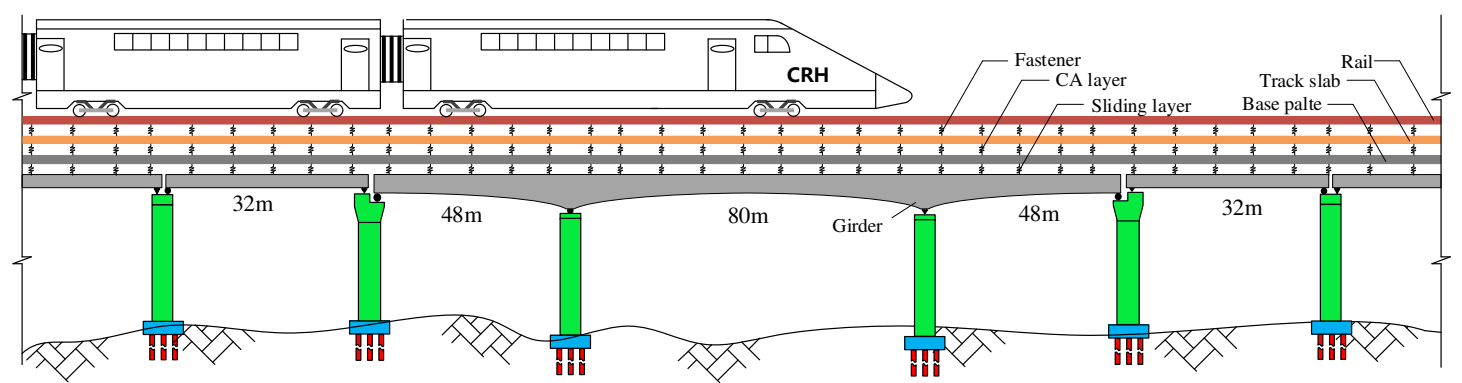

Fig. 2. TTBS model.

\section{Track irregularity}

\subsection{Initial irregularity}

Due to the inevitable deform of the rails during construction, installation and operation, the two rails deviate from the design position, that is, the initial track irregularity, which is usually divided into vertical, horizontal, directional and gauge irregularity. The irregularities of the track in all directions can actually be regarded as random fluctuations composed of various frequencies, phases and peak values. The power spectral density function is widely used in the mathematical expression of the track irregularity because it can clearly reflect the relationship between track irregularity and frequency, which generates track irregularity spectrum. Typical track spectrum includes American track spectrum, German track spectrum and China's ballastless track spectrum. Ballastless tracks are usually used for high-speed railways with a running velocity greater than $300 \mathrm{~km} / \mathrm{h}$, and the China's track spectrum is generated by using CRH2 test train to count a large number of ballastless track data. Therefore, the China's track spectrum is selected to describe the initial irregularity of the track in this study. The China's track spectrum adopts a power function to fit its irregularity, and the same formula is used to express the track spectrum in each wavelength section, as shown in the formula (9). 
In which, $S(f)$ represents the track spectrum, the unit is $\mathrm{mm}^{2} /(1 / \mathrm{m}) ; f$ is the spatial frequency of the track irregularity, the unit is $(1 / \mathrm{m}) ; A$ and $n$ are the coefficients of piecewise fitting, which are described in detail in code "PSD of ballastless track irregularities of high-speed railway" (NRA-PRC, 2014).

According to formula (9), the track initial irregularity power spectrum in all directions can be obtained. However, the above track irregularity power spectrum needs to be transformed into a displacement time history varying with mileage before it can be input into TTBS model, which can be converted in terms of trigonometric series method (Lai et al. 2020).

$$
\omega(x)=\sqrt{2} \sum_{k=1}^{N} \sqrt{S\left(\omega_{k}\right) \Delta \omega} \cos \left(\omega_{k} x+\phi_{k}\right)
$$

Where $S\left(\omega_{k}\right)$ represents the track irregularity power spectrum; $\omega_{k}$ is the selected frequency, the value of $k$ ranges 1 from $\mathrm{N}$, and $\omega_{1}$ and $\omega_{N}$ represent the minimum and maximum frequencies respectively; $\Delta \omega$ is the frequency space and $\phi_{k}$ presents the phase value of the $k$ th frequency.

Taking the initial gauge irregularity as an example, the irregular time sequence obtained varying with mileage (2000m) by transforming the China's track spectrum based on the trigonometric series method is shown in Fig. 3 .

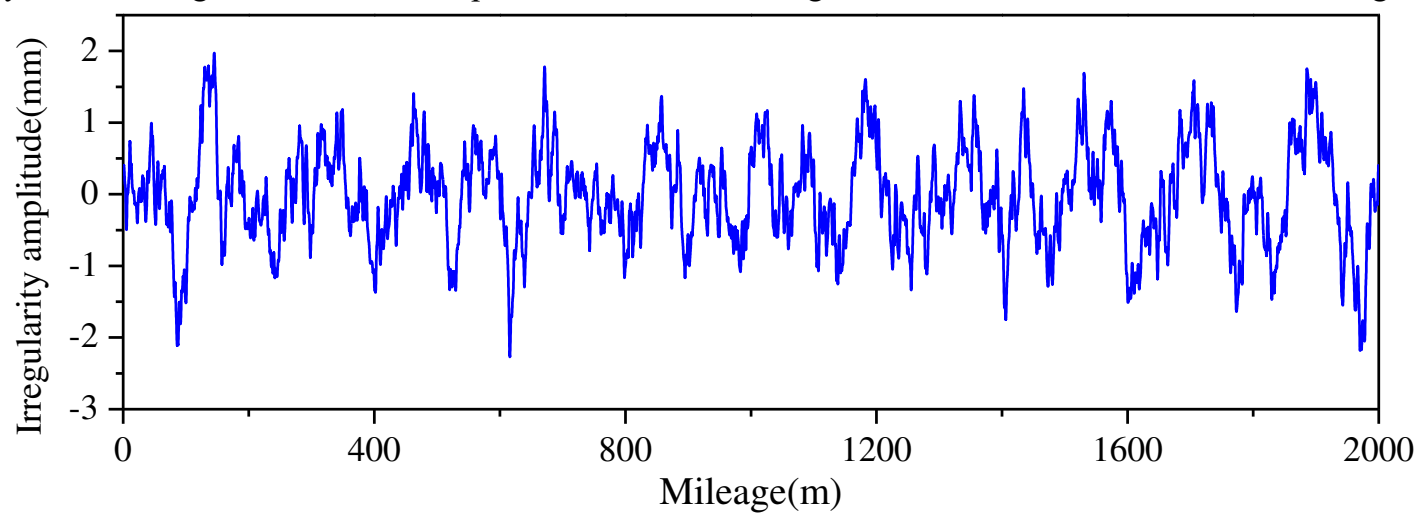

Fig. 3. Initial gauge irregularities.

\subsection{Additional irregularity}

In addition to the initial irregularity of the track, the additional irregularity occurs during the operation of the railway line due to the creep of the bridge, temperature effect, foundation settlement and earthquakes. The additional irregularity caused by lateral deformation of track under an action of earthquake seriously interferes with train safety and stability, therefore, this paper focuses on the additional irregularity caused by lateral deformation of track.

The spans of the HRGB may be deformed after the earthquake. Since the track and the bridge are tightly constrained in all directions, the bridge deformation will eventually reflect in the rail surface. Wei et al. (2018a, b, 2021) revealed that the track deformation at the girder joint reached the peak value under the influence of the horizontal component of seismic waves. This is because the span is disconnected at the joints, causing a weak connection, and the bridge deck is prone to relative displacement, which is reflected on the rail surface, which in turn causes the track to deform. To this end, choosing a combination of a HRGB of simply supported $(3 \times 32 m)+$ continuous $(48 m+80 m+48 m)+$ simply supported $(3 \times 32 \mathrm{~m})$, five types of lateral displacement forms at the position of girder joints are discussed, depicted in Fig. 4. In Fig. 4, T1 represents the second and the third span of simply supported bridge rotate in the same direction; $\mathrm{T} 2$ represents the second and the third span of simply supported bridge rotate reversely; T3 represents the second and the third span of 
simply supported bridge translate in reverse; T4 represents the adjacent spans of continuous bridge and simply supported bridge rotate in the same direction; T5 represents the adjacent spans of continuous bridge and simply supported bridge rotate reversely.
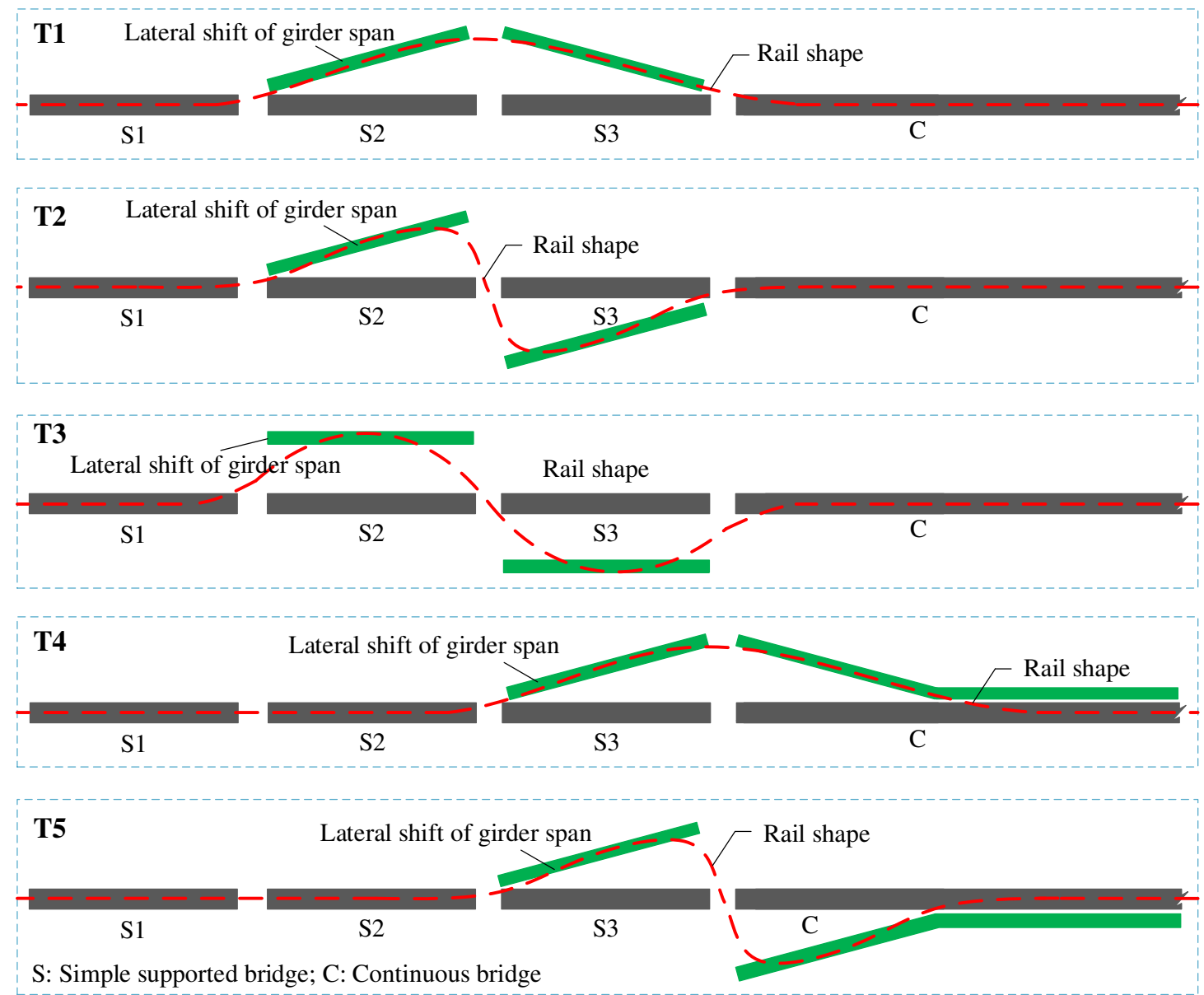

Fig. 4. 5 types of lateral deform of girder in HRGB after earthquake.

Taking the initial gauge irregularity as an example, the additional irregularity when the rail lateral deformation amplitude caused by the above five girder joint deform reaches $8 \mathrm{~mm}$ is superimposed, and the coupling irregularity is obtained as shown in Fig. 5.

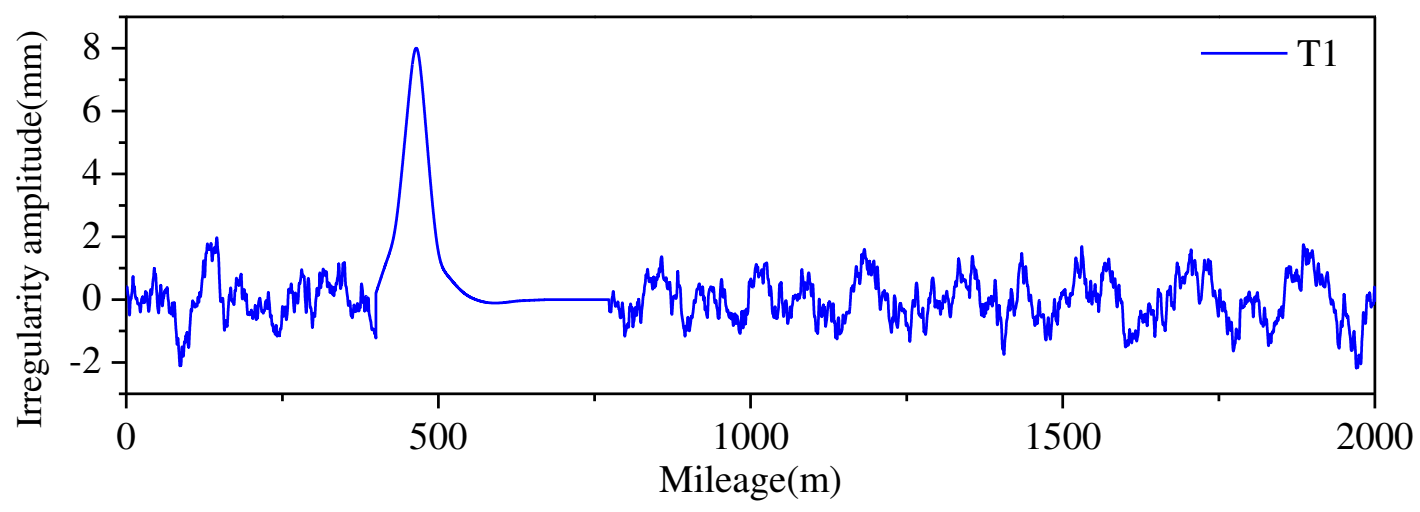




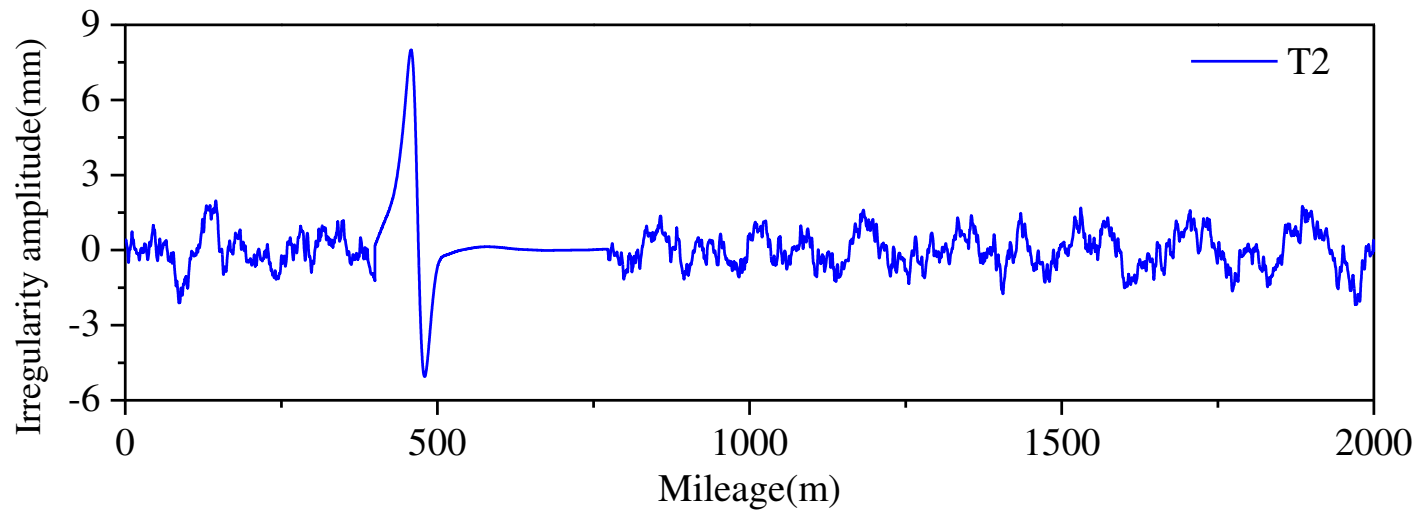

(b)

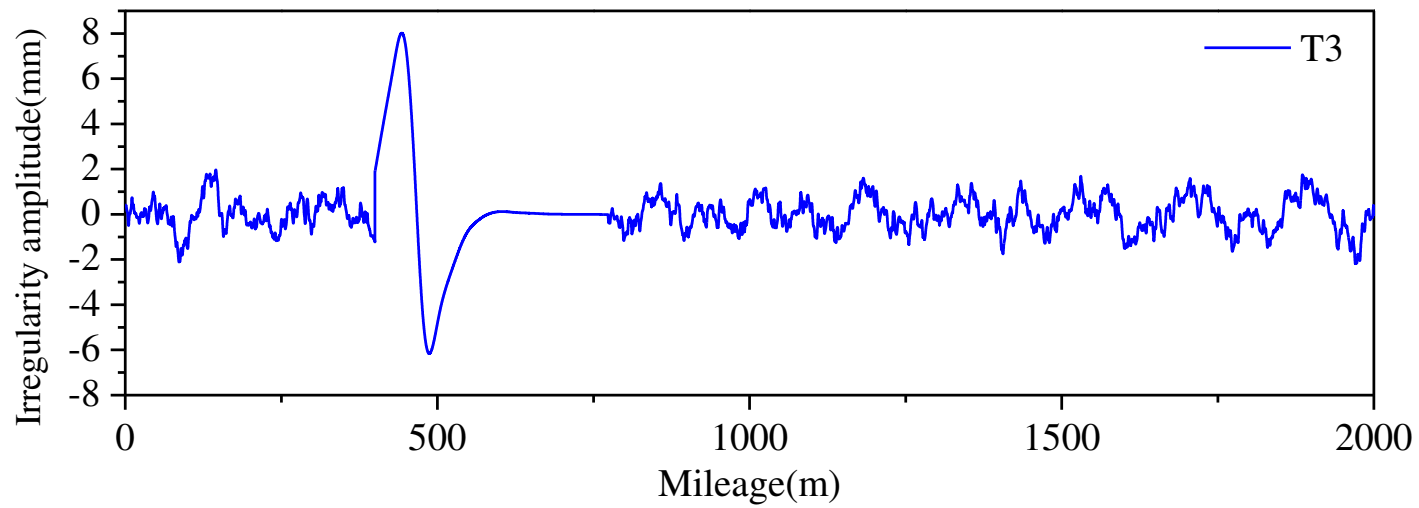

308
309

310

311

(c)

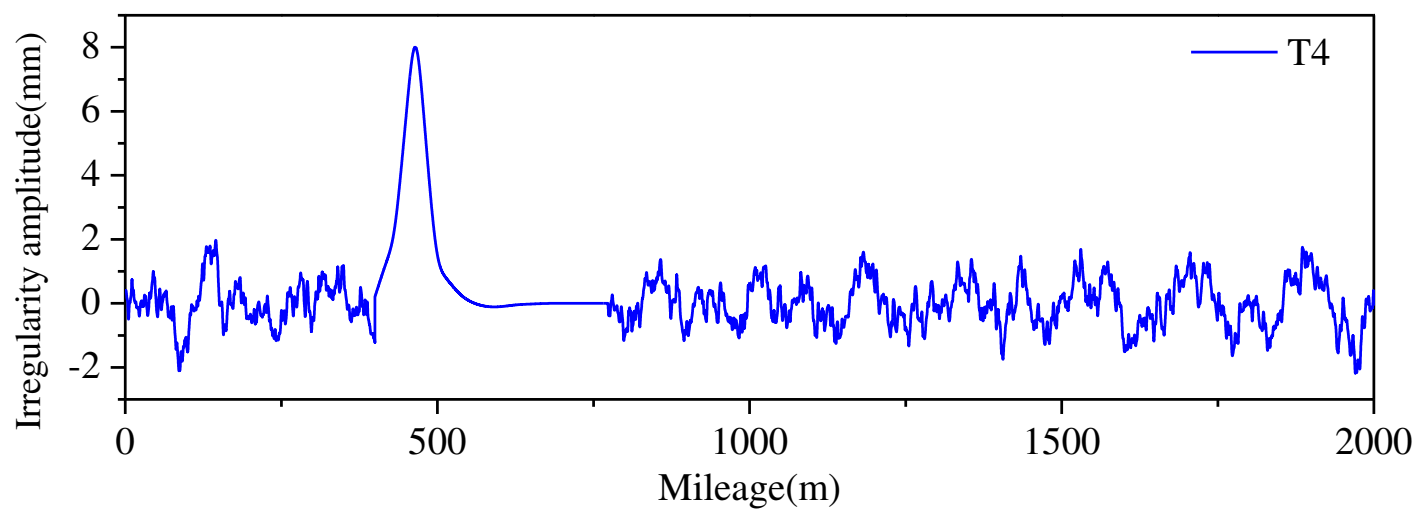

(d)

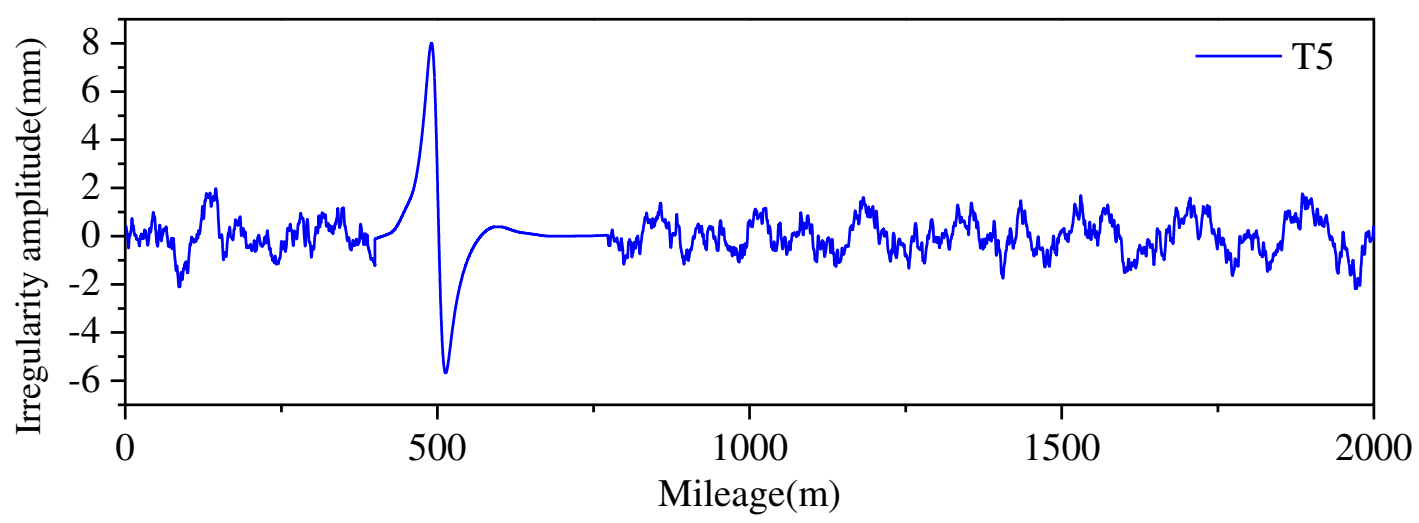

(e)

Fig. 5. Initial gauge irregularity superimposed with 5 types additional irregularity: (a) (e): Coupling irregularity 1 5. 


\subsection{Calculation process}

In this paper, by introducing the rail lateral displacement after the earthquake as the additional irregularity, the Matlab program is used to solve the train safety and stability indicators, and the influence of the types of lateral deform of girder, the amplitude of the lateral displacement of the rail and the train velocity on the driving safety and stability is analyzed. Finally, according to the track damage grade proposed in Section 2.3, the rail lateral displacement is determined as the damage quantification index of the track structure. The calculation process is depicted in Fig. 6.

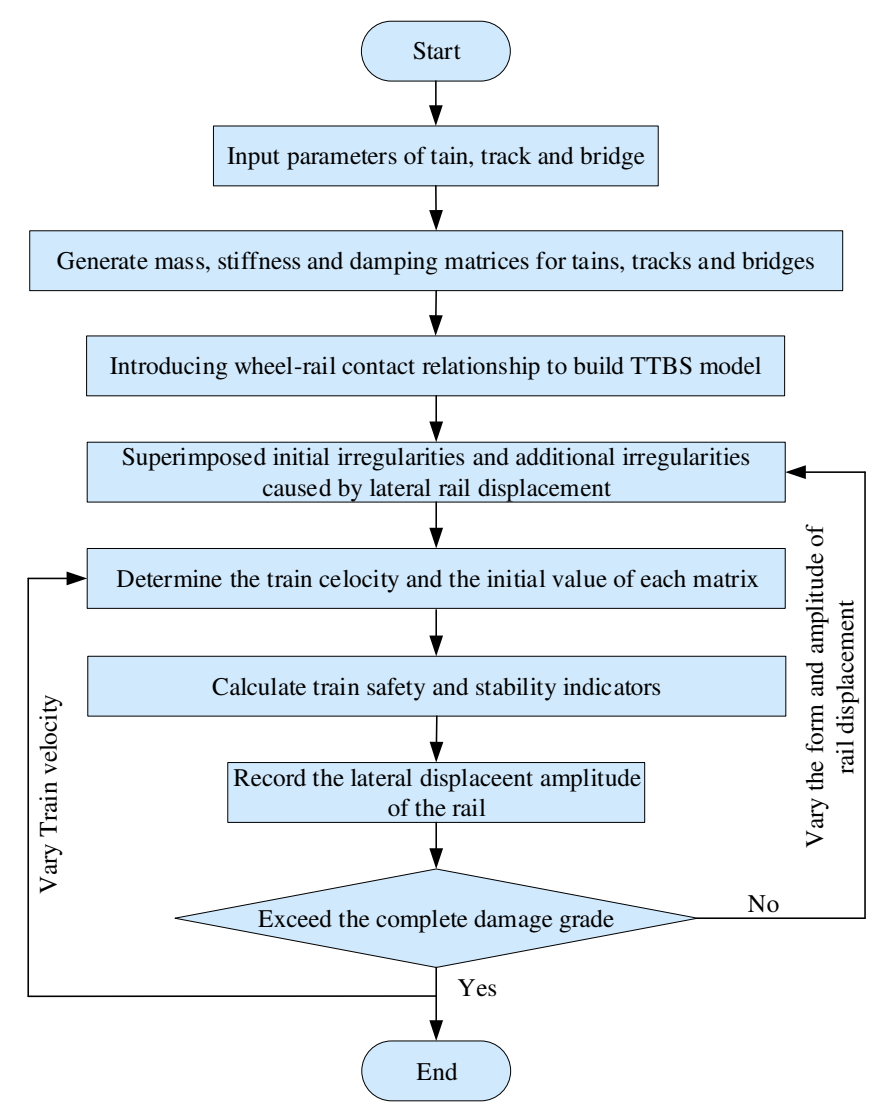

Fig. 6. Calculation flow chart.

\section{Results and discussion}

According to Fig. 6, the running velocity of the train is selected as $350 \mathrm{~km} / \mathrm{h}$ first, the transverse deformation amplitude of the rail caused by five types of girder deform in Fig. 4 is successively increased and superimposed with the initial track irregularity, and the corresponding train safety indexes, i.e. derailment coefficient value and wheel load reduction rate, and train stability indexes, i.e. car body lateral acceleration value and Sperling index, are calculated respectively. The calculation results are drawn in Fig. 7. 


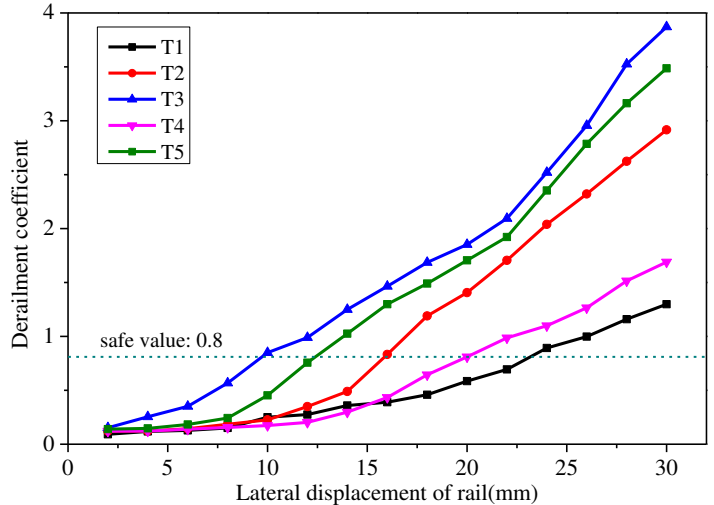

(a)

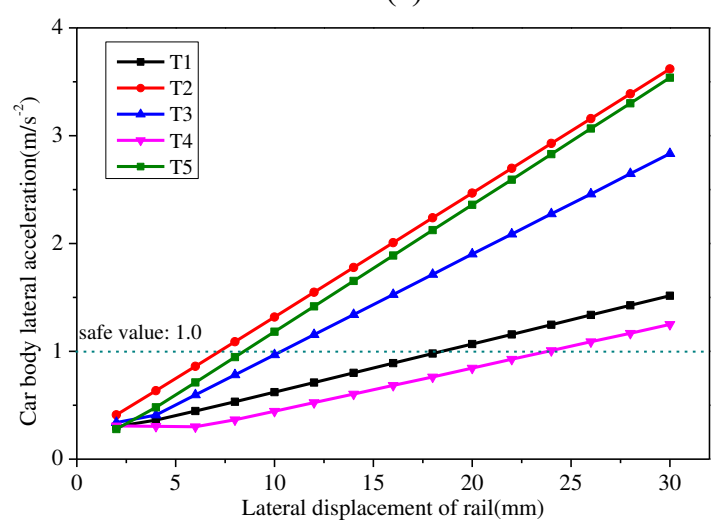

(c)

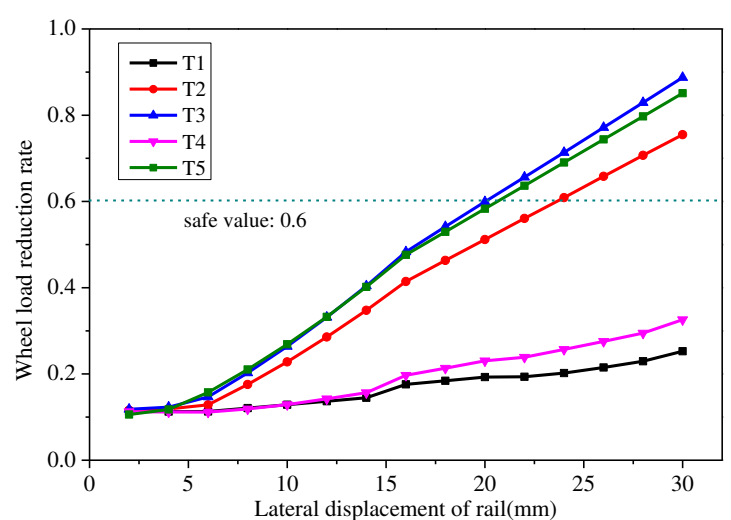

(b)

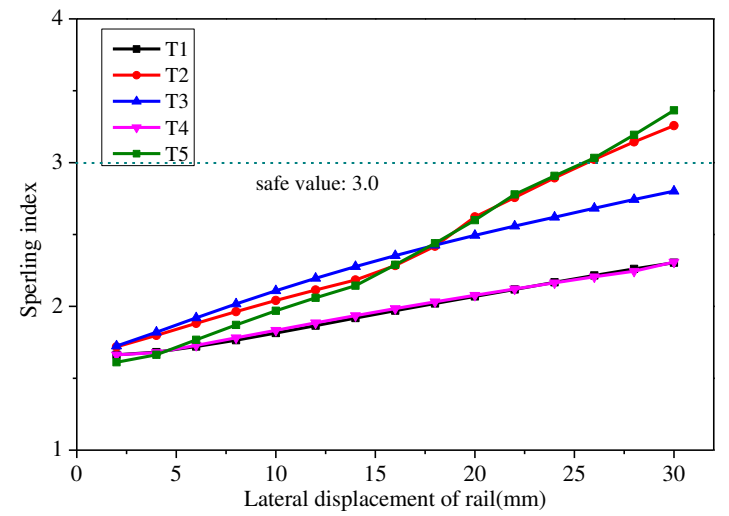

(d)

Fig. 7. Train safety and stability indexes corresponding to various types of girder deform $(350 \mathrm{~km} / \mathrm{h}):(\mathrm{a})$

Derailment coefficient; (b) Wheel load reduction rate; (c) Car body lateral acceleration; (d) Sperling index.

Fig. 7 indicates that all indexes of train operation increase with the rail lateral displacement amplitude. As the rail lateral displacement increases, the five types of girder deform can cause the derailment coefficient and the lateral acceleration of the car body to exceed the safe value (Fig. 7(a) and Fig. 7(c)). The lateral displacements of rails in type 1 to type 5 reaching the limit of derailment coefficient, namely 0.80 , are $23.0 \mathrm{~mm}, 15.8 \mathrm{~mm}, 9.6 \mathrm{~mm}, 20.0 \mathrm{~mm}$ and $12.5 \mathrm{~mm}$ respectively; The lateral displacements of rails in type 1 to type 5 reaching the limit value of lateral acceleration of car body, namely $1.0 \mathrm{~m} / \mathrm{s}^{-2}$, are $18.0 \mathrm{~mm}, 7.2 \mathrm{~mm}, 10.2 \mathrm{~mm}, 24.3 \mathrm{~mm}$ and $8.0 \mathrm{~mm}$ respectively. The wheel load reduction rate and Sperling index are not sensitive to some types of girder deform (Fig. 7(b) and Fig. 7(d)). When the lateral deformation of rail reaches $30 \mathrm{~mm}$, only the wheel load reduction rate caused by type 2, 3 and 5 exceeds the limit value, i.e. 0.60 , and the corresponding rail lateral deformation are $24.0 \mathrm{~mm}, 20.2 \mathrm{~mm}$ and $20.6 \mathrm{~mm}$; Only the Sperling index caused by type 2 and 5 exceeds the limit value, i.e. 3.0, and the corresponding rail lateral deformation is $25.2 \mathrm{~mm}$ and $25.3 \mathrm{~mm}$. From the perspective of the lateral deformation of the rail that exceeds the limit values of each train index, the third type of lateral deform of girder, that is, the lateral displacement of the rail caused by the reverse translation of the adjacent simply supported spans, has the greatest impact on the train safety; The second type of lateral deform of girder, that is, the 2nd and the 3rd span of simply supported girder bridge rotate reversely, has the greatest impact on the train stability.

Existing studies have shown that the influence of the train velocity on the train index cannot be ignored (Ju 2012; Lai et al. 2020). To this end, consider the above two types of lateral deform of girder respectively, increase the train velocity in steps of $50 \mathrm{~km} / \mathrm{h}$, and explore the impact of the velocity within the range of $200 \mathrm{~km} / \mathrm{h} \sim 400 \mathrm{~km} / \mathrm{h}$ on the indicators of train safety and stability.

Under the condition of the same rail lateral displacement, Fig. 8 presents that all train index values increase with the 
train velocity. However, the rail lateral displacement corresponding to the limit value of each train index decreases with the increase of the train velocity. It means that increasing the train velocity increases the threat to train safety and stability. Based on the track damage grade defined in Section 2.3, the lateral displacement of rail corresponding to each damage grade is also marked in Fig. 8, which is summarized in Table 4.

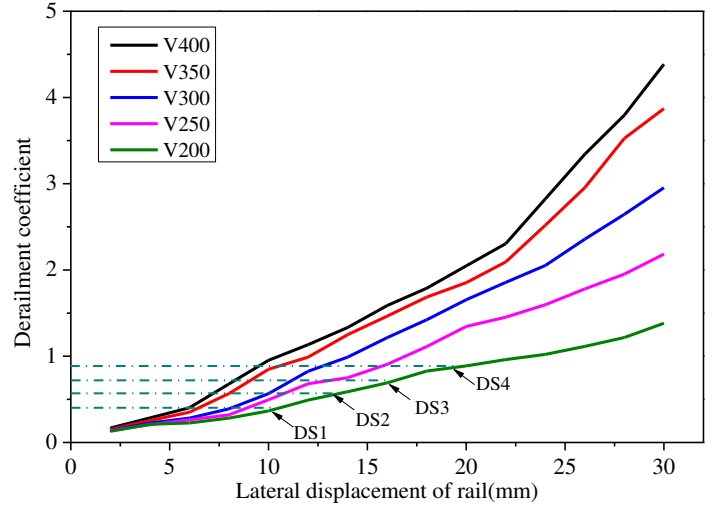

(a)

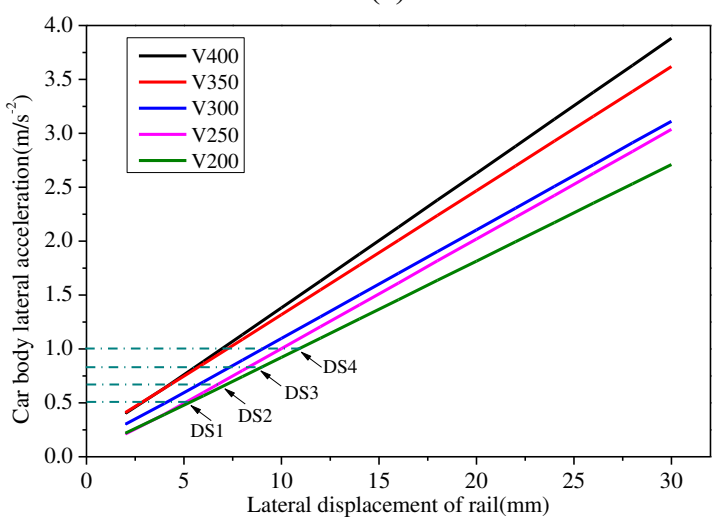

(c)

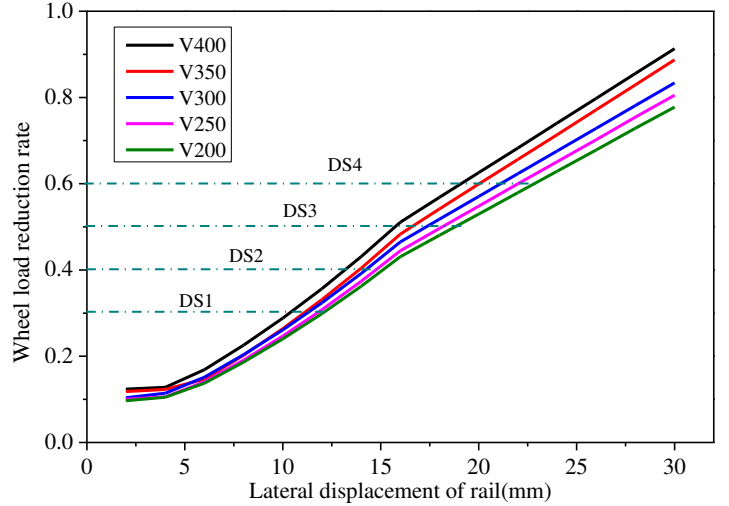

(b)

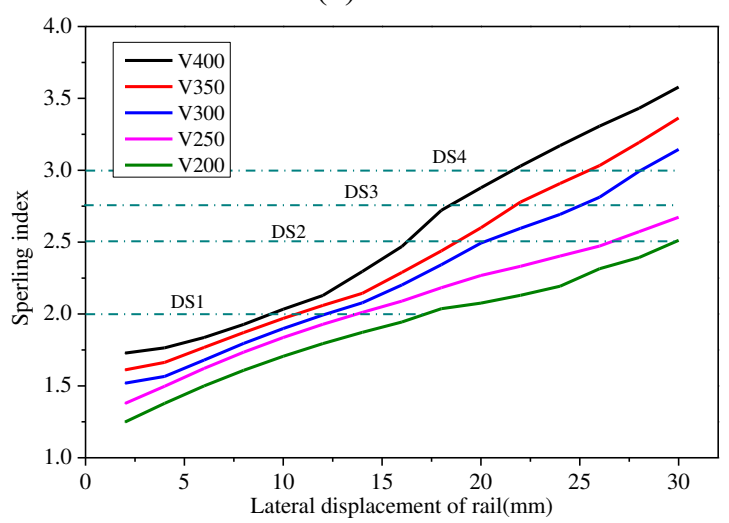

(d)

Fig. 8. Train safety and stability indexes corresponding to rail lateral deformation with various train velocity: (a)

Table 4 indicates that the rail lateral displacement corresponding to each damage grade based on the derailment coefficient is smaller than that based on the wheel load reduction ratio, which reveals that the rail lateral displacement determined by the derailment coefficient can more safely ensure the safety of trains. The rail lateral displacement corresponding to each damage grade obtained based on the lateral acceleration of the car body is smaller than the deformation value obtained based on the Sperling index. Similarly, the rail lateral displacement determined according to the lateral acceleration of the car body can more safely ensure the stability of the train.

Table 4. Lateral displacement of rail in each damage grade based on the definition of train safety and stability (mm).

\begin{tabular}{cccccc}
\hline Train index & Train velocity $(\mathrm{km} / \mathrm{h})$ & DS1 & DS2 & DS3 & DS4 \\
\hline & 400 & 6.0 & 6.8 & 7.9 & 8.8 \\
Derailment & 350 & 6.4 & 7.6 & 8.7 & 9.6 \\
coefficient & 300 & 8.1 & 9.5 & 10.8 & 11.8 \\
& 250 & 8.9 & 10.3 & 11.9 & 14.6 \\
& 200 & 10.5 & 12.7 & 15.7 & 17.6 \\
\hline Wheel load & 400 & 10.2 & 13.1 & 15.8 & 19.2 \\
\hline
\end{tabular}




\begin{tabular}{cccccc}
\cline { 2 - 5 } reduction rate & 350 & 11.0 & 13.8 & 16.8 & 20.2 \\
& 300 & 11.2 & 14.2 & 17.4 & 21.2 \\
& 250 & 11.8 & 14.8 & 18.2 & 22.2 \\
& 200 & 12.2 & 15.2 & 18.8 & 23.0 \\
\hline \multirow{3}{*}{ Car body lateral } & 400 & 2.7 & 4.2 & 5.6 & 6.9 \\
acceleration & 350 & 2.9 & 4.4 & 5.8 & 7.2 \\
& 300 & 4.1 & 5.7 & 7.4 & 9.0 \\
& 250 & 5.1 & 6.7 & 8.4 & 10.0 \\
\hline \multirow{2}{*}{ Sperling index } & 200 & 5.3 & 7.2 & 9.1 & 10.8 \\
\hline & 400 & 9.4 & 16.2 & 18.5 & 20.7 \\
& 350 & 10.8 & 18.8 & 21.8 & 25.2 \\
& 300 & 12.1 & 20.0 & 25.0 & 28.0 \\
& 250 & 13.8 & 26.5 & - & - \\
& 200 & 17.0 & 30.0 & - & - \\
\hline
\end{tabular}

According to the classification principle of rail damage grade, that is, taking the higher damage grade corresponding to the train safety and stability indicators (Section 2.3), the quantified value under various train velocity with the lateral displacement of the rail as the damage indicator is obtained, depicted in Fig. 9. Taking the train velocity of $350 \mathrm{~km} / \mathrm{h}$ for instance, while controlling the train safety and stability, the threshold values of the rail lateral displacement in intact, slight, moderate, severe and complete damage state are $2.9 \mathrm{~mm}, 4.4 \mathrm{~mm}, 5.8 \mathrm{~mm}$ and $7.2 \mathrm{~mm}$, respectively. It is worth noting that Fig. 9 only lists the critical values of rail lateral displacement corresponding to train velocity of $200 \mathrm{~km} / \mathrm{h}$, $250 \mathrm{~km} / \mathrm{h}, 300 \mathrm{~km} / \mathrm{h}, 3500 \mathrm{~km} / \mathrm{h}$ and $400 \mathrm{~km} / \mathrm{h}$, so the rail lateral displacement of other velocity within the range of $200 \mathrm{~km} / \mathrm{h}$ to $\sim 400 \mathrm{~km} / \mathrm{h}$ can be approximately taken by linear interpolation.

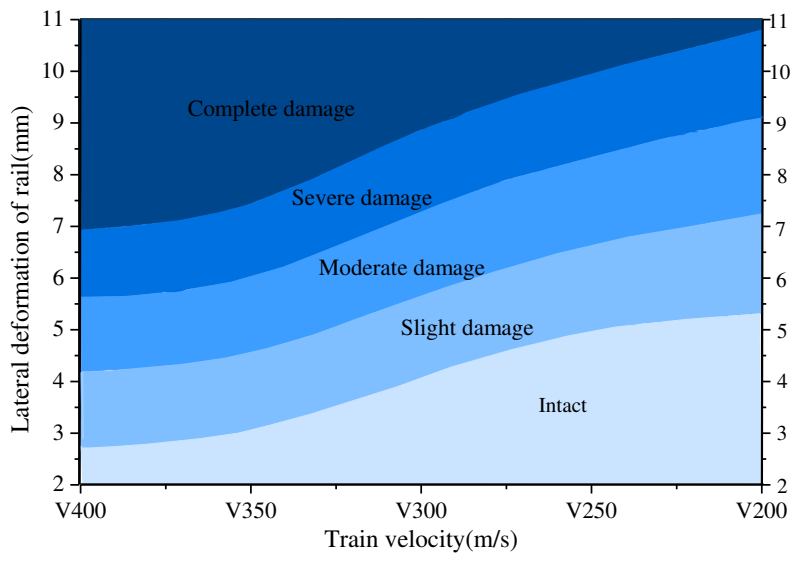

Fig. 9. Critical value of damage index of track structure.

\section{Conclusions}

This paper proposes to take the rail lateral displacement as the index to measure the damage of track structure of HRGBs, and investigates the influence of types of girder lateral deform, the amplitude of the lateral displacement and train velocity on the train safety and stability. Some conclusions are summed up as:

(1) According to the classification principle of damage grade in bridge structure, the track structure damage grade (intact, slight, moderate, severe and complete damage) is defined by refining the train safety and stability index thresholds.

(2) The derailment coefficient and the lateral acceleration of the train body are more sensitive to the girder lateral 
deform. The rail lateral displacement corresponding to the two exceeding the limit value is lower than the wheel weight reduction rate and the Sperling index. Therefore, using the derailment coefficient and the lateral acceleration of the train body as criteria can more safely access the train safety and stability.

(3) The rail lateral displacement caused by the reverse translation of the adjacent spans of simply supported bridge has the greatest impact on the train safety; the rail lateral displacement caused by adjacent spans of simply supported bridge rotate reversely has the greatest impact on the train stability.

(4) The lateral displacement of the rail corresponding to the various damage grades of the track within the scope of $200 \mathrm{~km} / \mathrm{h} \sim 400 \mathrm{~km} / \mathrm{h}$ is determined. Within this range, the rail lateral displacement corresponding to other speeds can be approximated by linear interpolation.

\section{Acknowledgements}

This study was funded by the National Natural Science Foundations of China under grant No. U1934207 and 51978667.

\section{Conflict of interest}

The authors declare that they have no known competing financial interests or personal relationships that could have appeared to influence the work reported in this paper.

\section{Ethical approval}

This article does not contain any studies with human participants or animals performed by any of the authors.

\section{Reference}

Cao S, Jiang L, Wei B (2019). Numerical and experimental investigations on the Park-Ang damage index for high-speed railway bridge piers with flexure failures. Eng Struct 201, 109851. https://doi.org/10.1016/j.engstruct.2019.109851

Chen Z, Zhai W (2020). Theoretical method of determining pier settlement limit value for China's high-speed railway bridges considering complete factors. Eng struct 209: 109998. https://doi.org/10.1016/j.engstruct.2019.109998

China Railway Design Group CO., LTD (2014). Code for Design of High Speed Railway (TB10621-2014). Beijing, China Railway Press.

Council AT (1996). ATC-32 Improved seismic design criteria for California bridges.

Dai G, Liu W (2013). Applicability of small resistance fastener on long-span continuous bridges of high-speed railway. J Central South Univ 20(5): 1426-1433. https://doi.org/10.1007/s11771-013-1631-7

Fema N (1999). Earthquake loss estimation methodology-HAZUS 99. Federal Emergency Management Agency and National Institute of Buildings Sciences, Washington DC, USA.

Gou H, Yang L, Leng D, Bao Y, Pu Q (2018). Effect of bridge lateral deformation on track geometry of high-speed railway. Steel Compos Struct 29(2): 219-229. https://doi.org/10.12989/scs.2018.29.2.219

Gou H, Yang L, Mo Z, Guo W, Shi X, Bao Y (2019). Effect of long-term bridge deformations on safe operation of high-speed railway and vibration of vehicle-bridge coupled system. Int J Struct Stab Dyn 19(9): 640-660. https://doi.org/10.1142/S0219455419501116

Hu Z, Wei B, He X, Jiang L, Li S (2022). Effects of Spatial Variation of Ground Motion (SVGM) on Seismic Vulnerability of Ultra-high tower and Multi-tower Cable-stayed Bridges. J Earthq Eng ID: 1991517 
https://doi.org/10.1080/13632469.2021.1991517

Hu Z, Wei B, Jiang L, Li S, Yu Y, Xiao C (2022). Assessment of optimal ground motion intensity measure for high-speed railway girder bridge (HRGB) based on spectral acceleration. Eng Struct 252. 113728. https:// doi.org/10.1016/j.engstruct.2021.113728

Jiang C, Wei B, Wang D, Jiang L, He X (2017). Seismic Vulnerability Evaluation of a Three-Span Continuous Beam Railway Bridge. Math Problems Eng 1-13. https://doi.org/10.1155/2017/3468076

Jin Z, Pei S, Li X, Liu H, Qiang S (2016). Effect of vertical ground motion on earthquake-induced derailment of railway vehicles over simply-supported bridges. J Sound Vib 383: 277-294. https://doi.org/10.1016/j.jsv.2016.06.048

Jin Z, Liu W, Pei S, He J (2020). Probabilistic assessment of vehicle derailment based on optimal ground motion intensity measure. Vehicle Syst Dyn 59(11): 1781-1802 https://doi.org/10.1080/00423114.2020.1792940

Ju S (2012). Nonlinear analysis of high-speed trains moving on bridges during earthquakes. Nonlinear Dyn 69(1-2): 173-183. https://doi.org/10.1007/s11071-011-0254-5

Kang X, Jiang L, Bai Y, Caprani C (2017). Seismic damage evaluation of high-speed railway bridge components under different intensities of earthquake excitations. Eng Struct 152: 116-128. https://doi.org/10.1016/j.engstruct.2017.08.057

Kowalsky M (2000). Deformation limit states for circular reinforced concrete bridge columns. J Struc Eng 126(8): 869-878. https://doi.org/10.1061/(ASCE)0733-9445(2000)126:8(869)

Lai Z, KangX, Jiang L, Zhou W, Feng Y, Zhang Y, Yu J, Nie L (2020). Earthquake influence on the rail irregularity onhigh-speed railway bridge. Shock Vib (2): 1-16. https://doi.org/10.1155/2020/4315304

Lai Z, Jiang L, Liu X, Zhang Y, Zhou W (2020). Analytical investigation on the geometry of longitudinal continuous track in high-speed rail corresponding to lateral bridge deformation. Constr Build Mater 268. 121064. https://doi.org/10.1016/j.conbuildmat.2020.121064

Lai Z, Jiang L, Zhou W, Yu J, Zhang Y, Liu X, Zhou W (2021). Lateral girder displacement effect on the safety and comfortability of the high-speed rail train operation. Vehicle Syst Dyn 1-25. https://doi.org/10.1080/00423114.2021.1942507

Liu X, Jiang L, Lai Z, Xiang P, Chen Y (2020). Sensitivity and dynamic analysis of train-bridge coupled system with multiple random factors. Eng Struct 221: 111083. https://doi.org/10.1016/j.engstruct.2020.111083

Luo X (2005). Study on methodology for running safety assessment of trains in seismic design of railway structures. Soil Dyn Earthq Eng 25(2): 79-91. https://doi.org/10.1016/j.soildyn.2004.10.005

Ministry of Railway of People's Republic of China (MR-PRC) (1993). Specification for dynamic performance testing verification method and assessment of railway locomotive (TB/T 2360-1993). Beijing, China Railway Press.

Ministry of Railway of People's Republic of China (MR-PRC) (2008). Testing of High-speed Electic Multiple Unit on Completion of Construction. Beijing, China Railway Press.

National Railway Administration of the People's Republic of China (NRA-PRC) (2014). PSD of ballastless track irregularities of high-speed railway (TB/T 3352-2014). Beijing, China Railway Press.

Nielson B, DesRoches R (2007). Seismic fragility methodology for highway bridges using a component level approach. Earthq Eng Struct Dyn 36(6): 823-839. https://doi.org/10.1002/eqe.655

Pan Y, Agrawal A, Ghosn M (2007). Seismic fragility of continuous steel highway bridges in New York state. J Bridge Eng 12(6): 689-699. https://doi.org/10.1061/(ASCE)1084-0702(2007)12:6(689)

Park J, Towashiraporn P (2014). Rapid seismic damage assessment of railway bridges using the response-surface statistical model. Struct Saf 47:1-12. https://doi.org/10.1016/j.strusafe.2013.10.001

Shen Z, Hedrick J, Elkins J (2007). A comparison of alternative creep force models for rail vehicle dynamic analysis. 
Vehicle Syst Dyn 12(1-3):79-83. https://doi.org/10.1080/00423118308968725

Wei B, Yang T, Jiang L, He X (2018a). Effects of friction-based fixed bearings on the seismic vulnerability of a high-speed railway continuous bridge. Adv Struct Eng 21(5): 643-657. https://doi.org/10.1177/1369433217726894

Wei B, Zuo C, He X, Jiang L, Wang T(2018b). Effects of vertical ground motions on seismic vulnerabilities of a continuous track-bridge system of high-speed railway. Soil Dyn Earthq Eng 115: 281-290. https://doi.org/10.1016/j.soildyn.2018.08.022

Wei B, Li C, He X (2019). The Applicability of Different Earthquake Intensity Measures to the Seismic Vulnerability of a High-Speed Railway Continuous Bridge. Int J Civ Eng 17(7): 981-987. https://doi.org/10.1007/s40999-018-0347-3

Wei B, Wang W, Wang P, Yang T, Jiang L, Wang T (2020). Seismic Responses of a High-speed Railway (HSR) Bridge and Track Simulation under Longitudinal Earthquakes. J Earthq Eng (3): 1-22. https://doi.org/10.1080/13632469.2020.1832937

Wei B, Hu Z, Zuo C, Wang W, Jiang L (2021). Effects of horizontal ground motion incident angle on the seismic risk assessment of a high-speed railway continuous bridge. Arch Civ Mech Eng 21(1): 1-20. https://doi.org/10.1007/s43452-020-00169-0

Xiang P, Wei M, Sun M, Li Q, Jiang L, Liu X, Ren J (2021). Creep Effect on the Dynamic Response of Train-Track-Continuous Bridge System. Int J Struct Stab Dyn 21.2150139. https://doi.org/10.1142/S021945542150139X

Yan B, Liu S, Pu H, Dai G, Cai Y(2017). Elastic-plastic seismic response of CRTS II slab ballastless track system on high-speed railway bridges. Sci China Tech Sci 60(6): 865-871. https://doi.org/10.1007/s11431-016-0222-6

Yu J, Jiang L, Zhou W, Lu J, Zhong T, Peng K(2021). Study on the influence of trains on the seismic response of high-speed railway structure under lateral uncertain earthquakes. B Earthq Eng 19(7): 2971-2992. https://doi.org/10.1007/s10518-021-01085-1

Yu Z, Li H, Wei B, Jiang L, Mao J (2017). Numerical analysis on longitudinal seismic responses of high-speed railway bridges isolated by friction pendulum bearings. J Vib 4(4): 1748-1760. https://doi.org/10.21595/jve.2017.18557

Zhai W, Xia H, Cai C, et al (2013). High-speed train-track-bridge dynamic interactions-part I: theoretical model and numerical simulation. Int J Rail Transport 1(1-2): 3-24. https://doi.org/10.1080/23248378.2013.791498

Zhang X, Shan Y, Yang X (2017). Effect of bridge-pier differential settlement on the dynamic response of a high-speed railway train-track-bridge system. Math Probl Eng 1-13. https://doi.org/10.1155/2017/8960628

Zheng L, Jiang L, Feng Y, Liu X, Zhou W (2020). Effects of foundation settlement on comfort of riding on high-speed train-track-bridge coupled systems. Mech Based Des Struct 1-19. https://doi.org/10.1080/15397734.2020.1784204 